\title{
Iron Deficiency in the Rat: Effects on Oxidative Metabolism in Distinct Types of Skeletal Muscle
}

\author{
BRUCE MACKLER, ${ }^{(16)}$ RICHARD GRACE, AND C. A. FINCH \\ Departments of Pediatrics and Medicine, and the Child Development and Mental Retardation Center, \\ Seattle, Washington, USA
}

\begin{abstract}
Summary
Studies performed on iron-deficient and control rats demonstrated that oxidative energy production (phosphorylation) by mitochondria from iron-deficient red and intermediate skeletal muscles was greatly reduced with pyruvate-malate, succinate, and $\alpha$-glycerophosphate as substrates. Although phosphorylation was also decreased in iron-deficient white skeletal muscle with succinate and pyruvate-malate as substrates, no change was found with $\alpha$-glycerophosphate as substrate.
\end{abstract}

\section{INTRODUCTION}

Previously, we $(4,6)$ have shown that a limited running ability due to iron deficiency in rats may result from decreased levels in skeletal muscle mitochondria of $\alpha$-glycerophosphate oxidase, and NADH and succinic oxidases which are all iron-containing enzymes and components of the terminal electron transport systems. Studies by other investigators $(2,9)$ suggest that the mitochondrial $\alpha$-glycerophosphate system in mammals is present mainly in skeletal muscle containing pale muscle fibers (white muscle) and to a much lesser degree in muscle containing mostly red fibers (red and intermediate muscle). It is well established that the work capacity of an animal is dependent on the slower contracting red and intermediate types of muscle, and not on the fast contracting white muscle which is important for quick movements but not sustained activity (7). It was of interest therefore to determine the effects of iron deficiency on the terminal oxidase systems in mitochondria from the different muscle types of rats so as to establish whether the systems are of importance in work performance in iron-deficient rats.

\section{MATERIALS AND METHODS}

Male Sprague-Dawley rats were obtained at $4 \mathrm{wk}$ of age, $1 \mathrm{wk}$ after weaning. Iron deficiency was induced by feeding the animals a low iron diet, prepared in our laboratory as described by ICN Nutritional Biochemicals, Cleveland, $\mathrm{OH}$, that contained 5-8 $\mathrm{mg} / \mathrm{kg}$ iron. After $6 \mathrm{wk}$ on this diet, hemoglobin concentrations were determined and studies performed only on rats with hemoglobin concentrations of less than $7 \mathrm{~g} / 100 \mathrm{ml}$ blood. Previously, we have shown that the low hemoglobin concentrations found in rats fed the low iron diet were accompanied by greatly lowered levels of plasma iron and increased total iron binding capacity and that the anemia was of a microcytic type $(4,5,14)$. The control groups were fed the low iron diet during the experimental period, but received weekly intraperitoneal injections of $5 \mathrm{mg}$ of iron in the form of iron dextran (Imferon, MerrellNational Labs). All animals were allowed food and water ad libitum. The iron-deficient rats consumed over $90 \%$ of the amount of diet eaten by the control animals and on the average were only approximately $5 \%$ smaller by weight than the control animals. This suggests that severe caloric malnutrition was not present.

Rats were killed by cervical dislocation. The muscles of the hind and fore legs were removed and separated into red, white, and intermediate types. Muscle mitochondria were prepared from the three types of muscle as described by Makinen and Lee (12). Oxidative phosphorylation was studied polarographically at $25^{\circ} \mathrm{C}$ with a Clark oxygen electrode (Yellow Springs Instrument Co., Yellow Springs, OH) fitted to a closed glass thermostated chamber (Gilson Medical Electronics Inc., Middleton, WI) as described previously $(3,6,8)$.

ADP content of standard solutions was determined by the method of Adam (1). Protein was determined by the method of Lowry et al. (10), and hemoglobin was determined as cyanmethemoglobin with standards employed for calibration (Hycel, Inc., Houston, TX). Statistical analyses were performed by standard methods of variance as described by Snedecor and Cohran (15).

Crystalline bovine serum albumin (fraction V), ADP, Tris, and EDTA were obtained from Sigma Chemical Co., St. Louis, MO. Nagase was obtained from Biddle Sawer Corp., New York.

\section{RESULTS AND DISCUSSION}

Mitochondria isolated from the distinct types of skeletal muscle from control and iron-deficient rats were studied for their ability to perform oxidative phosphorylation with pyruvate-malate, succinate, and $\alpha$-glycerophosphate as substrates. As shown in Table 1 , mitochondria prepared from the different muscle types of control animals phosphorylated well with all of the substrates as shown by high ADP:O ratios and high values for the respiratory control index which measures how well oxygen utilization is coupled to phosphorylation in the preparations. Rates of phosphorylation (as measured by ADP esterification) were higher in red and intermediate control muscle mitochondria than in white muscle mitochondria with pyruvate-malate and succinate as substrates; however, with $\alpha$-glycerophosphate as substrate rates of phosphorylation by mitochondria from red muscle were moderately but not greatly lower (approximately $35 \%$ ) than rates of phosphorylation by intermediate and white muscle mitochondria. Mitochondrial preparations from all muscle types of iron-deficient animals had markedly reduced abilities to phosphorylate and were not as well coupled as control mitochondria as shown by reduced values for the respiratory control index and decreased rates of ADP esterification when pyruvatemalate and succinate were used as substrates (Table 1). Rates of phosphorylation were also significantly reduced in red and intermediate iron-deficient muscle with $\alpha$-glycerophosphate as substrate, but not in white muscle where the rate of ADP esterification remained unchanged from control values.

In conclusion, oxidative energy production by mitochondria from red and intermediate muscle (slow contracting muscle necessary for sustained activity and work performance) from iron-deficient rats was markedly and significantly reduced as 
Table 1. Effects of iron deficiency on oxidative phosphorylation in mitochondria from the three types of skeletal muscle of rats

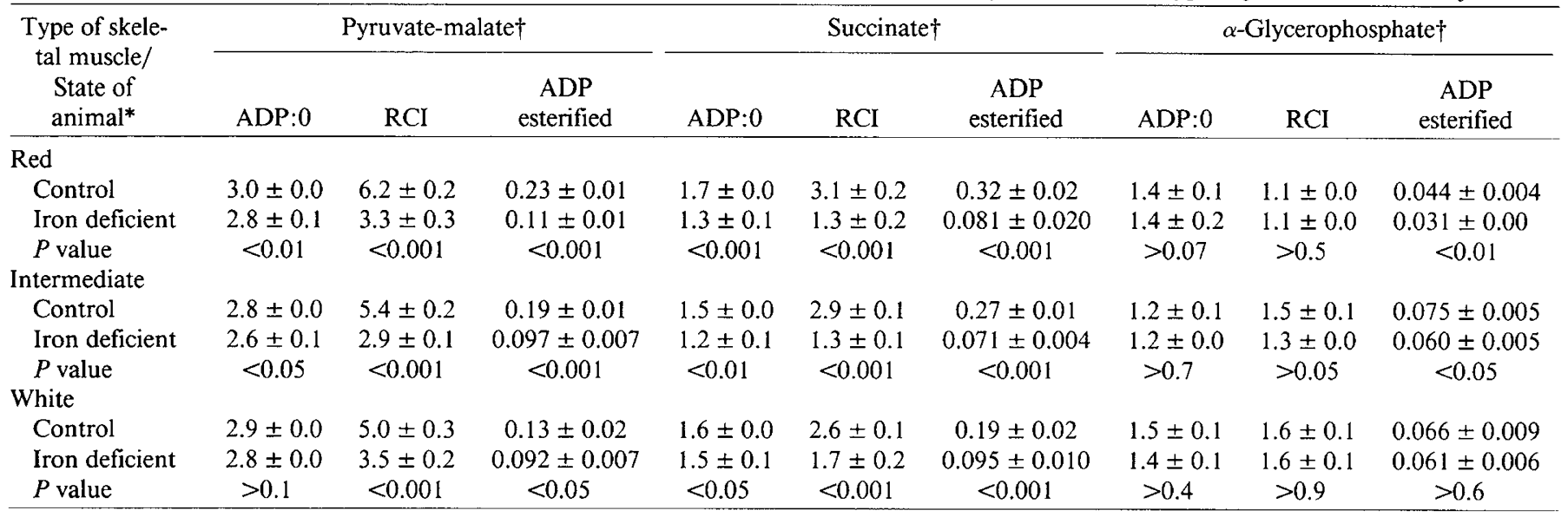

* The mean hemoglobin concentrations of the control and iron-deficient rats were $14.9 \pm 0.2$ and $5.6 \pm 0.1( \pm \mathrm{SE})$, respectively.

$\dagger$ Activities were defined as follows: ADP esterified: $\mu$ mol ADP phosphorylated per minute per milligram of protein; RCI (respiratory control index) was calculated as the ratio of State 3 rate of oxidation to State 4 rate of oxidation. All values represent the means of data from at least eight separate experiments \pm the SE.

measured by rates of phosphorylation with pyruvate-malate succinate and $\alpha$-glycerophosphate as substrate. The results are in accord with findings in our previous studies on preparations from unseparated pooled muscle $(1,2,4,6)$ and with the more recent reports of other workers $(11,13,14,15)$. These results suggest strongly that iron deficiency results in defective oxidative energy metabolism in red and intermediate skeletal muscle with greatly decreased production of ATP, and decreased activity of the $\alpha$-glycerophosphate shuttle which is necessary for the conversion of cytoplasmic NADH to NAD and continued operation of glycolysis. These metabolic alterations result in excess lactate formation, which at high levels leads to cessation of physical activity (4). It is of interest that the $\alpha$-glycerophosphate shuttle is not affected in white muscle (which is not of importance in prolonged physical activity) although ATP formation by NADH and succinate is markedly decreased.

\section{REFERENCES AND NOTES}

1. Adam, H.: Adenosine-5'-diphosphate and adenosine-5'-monophosphate. In: H-U. Bergmeyer: Methods of Enzymatic Analysis. pp. 573-577 (Academic Press Inc., New York, 1965).

2. Bass, A., Brdiczka, D., Eyer, P., Hofer, S., and Pette, D.: Metabolic differentiation of distinct muscle types at the level of enzymatic organization. Eur. J. Biochem., 10: 198 (1969).

3. Chance, B. and Williams, G. R.: Respiratory enzymes in oxidative phosphorylation: I. Kinetics of oxygen utilization. J. Biol. Chem., 217: 383 (1955).

4. Finch, C. A., Gollnick, P.D., Hlastala, M. P., Miller, L. R., Dillmann, E., and Mackler, B.: Lactic acidosis as a result of iron deficiency. J. Clin. Invest., 64 . 129 (1979).

5. Finch, C. A., Huebers, H. A., Miller, L. R., Josephson, B. M., Shepard, T. H., and Mackler, B.: Fetal iron balance in the rat. Am. J. Clin. Nutr., 37: 910 (1983).

6. Finch, C. A., Miller, L. R., Inamdar, A. R., Person, R., Seiler, K., and Mackler, B.: Iron deficiency in the rat: physiological and biochemical studies of muscle dysfunction. J. Clin. Invest., 58: 447 (1976).

7. Henneman, E.: Peripheral mechanisms involved in the control of muscle. In: Vernon B. Mountcastle: Medical Physiology Vol. 1, pp. 617, 623; (C. V. Mosby Co. Publishers, St. Louis, 1974).

8. Inamdar, A. R., Person, R., Kohnen, P., Duncan, H., and Mackler, B.: Effect of age on oxidative phosphorylation in tissues of hamsters. J. Gerontol., 29: 638 (1974).

9. Khan, M. A.: On the subsarcolemmal localization of phenazine ethosulfatelinked $\alpha$-glycerophosphate dehydrogenase activity in pigeon pectoralis white muscle fibers. Histochemistry, 50:103 (1976).

10. Lowry, O. H., Rosebrough, N. J., Farr, A. L., and Randall, R. J.: Protein measurement with the Folin phenol reagent. J. Biol. Chem., 193: 265 (1951).

11. Maguire, J. J., Davies, K. J. A., Dallman, P. R., and Packer, L.: Effects of dietary iron deficiency on iron-sulfur proteins and bioenergetic functions of skeletal muscle mitochondria. Biochim. Biophys. Acta, 679: 210 (1982).

12. Makinen, M. W. and Lee, C. P.: Biochemical studies of skeletal muscle mitochondria. I. Microanalysis of cytochrome content, oxidative and phosphorylative activities of mammalian skeletal muscle mitochondria. Arch. Biochem. Biophys., 126: 75 (1968).

13. McLane, J. A., Fell, R. D., McKay, R. H., Winder, W. W., Brown, E. B., and Holloszy, J. O.: Physiological and biochemical effects of iron deficiency on rat skeletal muscle. Am. J. Physiol. 214: C47 (1981).

14. Shepard, T. H., Mackler, B., and Finch, C. A.: Reproductive studies in the iron-deficient rat. Teratology, 22: 329 (1980).

15. Snedecor, G. W., Cochran, W. G.: Statistical Methods. 6th ed., pp. 258-298 (Iowa State University Press, Ames, 1974).

16. Requests for reprints should be addressed to: Dr. Bruce Mackler, University of Washington, Department of Pediatrics, RD-20, Seattle, Washington 98195.

17. This research was supported in part by grant HD-15915, GM-23006, HD02274 , and HL-06242 from the National Institutes of Health.

18. Received for publication April 19, 1983.

19. Accepted for publication September 12, 1983. 